\title{
Investigating the characteristics of MOOCs according to eight critical dimensions: A case study
}

\author{
Jennifer W.M. Lai, Matt Bower, Yvonne Breyer and John De Nobile \\ Macquarie University
}

\begin{abstract}
Massive Open Online Courses (MOOCs) have been a popular trend in the online learning landscape. However, MOOC learners have expressed their dissatisfaction with the courses or problems with course management. To develop a widely accepted MOOC, the main aim of this study is to investigate the characteristics of MOOCs by using eight themes: learning outcomes, affective elements, behaviours, design, technology elements, pedagogy, presence and institutional environment. Using the case study approach, we explored the practices of four MOOCs in an Excel specialisation by using student unsolicited feedback, the literature and the analysis of the MOOCs by researchers. We analysed the learners' posts on the official forums with auto-code sentiment and text search functions in Nvivo 12 Plus. The results of this study showed that high-rated MOOCs had approximately $74.7 \%$ of positive sentiments on discussion forums, with $1.2 \%$ negative and $24.1 \%$ neutral. The results indicated that MOOCs helped learners improve their level of knowledge in the subject area. Teachers/instructors also play a very significant role, and they have to provide clear explanations in different concepts. To conclude, this study intends to offer guidelines to researchers, educators, and MOOC designers to create successful MOOCs by focusing on the eight dimensions.
\end{abstract}

Keywords: MOOCs, MOOCs evaluation, Excel, characteristics, educational technology

\section{Introduction}

With the growth of different varieties of online tools and spaces, online learning is becoming part of our lives. Many higher education institutions have taken this opportunity to reach new cohorts of learners both locally and internationally by offering Massive Open Online Courses (MOOCs). However, the completion rates of MOOC appeared to be comparatively low (Gütl, Rizzardini, Chang, \& Morales, 2014), and MOOC learners had expressed their dissatisfaction with the courses or course management (Khalil \& Ebner, 2015). Researchers also commented that MOOC platforms did not provide enough opportunities to allow for synchronous interaction with instructors or peers (Atiaja \& Proenza, 2016).

Recently, scholars conducted studies to identify the success factors, best practices or effectiveness of a MOOC (Gamage, Fernando, \& Perera, 2015; Khalil \& Ebner, 2015; Loizzo, Ertmer, Watson, \& Watson, 2017; Walker \& Loch, 2014). For instance, Gamage et al. (2015) proposed that assessment, pedagogy, technology, content, motivation, learner support or interactivity affected the effectiveness of a MOOC. Loizzo et al. (2017) argued that a successful MOOC enabled participants to gain knowledge and understand course materials. Also, success was tied to learner's motivation and enjoyment of the MOOC and the applicability of knowledge gained in everyday life. Furthermore, Walker and Loch (2014) stressed that MOOC success could be linked to the quality of resources and the style of courses. Although previous studies had investigated the effectiveness of MOOCs, the results were doubtful as there was a lack of suitable tools to evaluate the MOOC itself (Zhao, Wu, Chen, \& Wan, 2017).

A recent systematic literature review (Lai \& Bower, 2019) examined which themes were evaluated when using technology in an educational context by evaluating empirical studies in a range of different education levels, disciplines and technologies. Eight dimensions were identified in the review, namely learning outcomes, affective elements, behaviour, design, technology, teaching/pedagogy, presence/community and institutional environment. These eight dimensions provided an analytical framework that educators and researchers could use to investigate the characteristics of MOOCs holistically.

In addition to the eight dimensions, previous researchers had used student reviews and analysed the sentiments of feedback to evaluate MOOCs (e.g., Adamopoulos, 2013; Moreno-Marcos, Alario-Hoyos, Muñoz-Merino, 
Estévez-Ayres, \& Kloos, 2018; Wen, Yang, \& Rose, 2014). Wen et al. (2014) argued that learner feedback forum was the natural place where participants conveyed their sentiments, satisfaction or dissatisfaction with the course. Sentiment analysis was the study of people's sentiments, attitudes, evaluations, opinions and/or emotions towards organizations, services, products and so on (Sharef, 2014). Sentiment analysis was one of the great accomplishments of the last decade in the field of Language Technologies (Wen et al., 2014, p. 130).

These sentiments could be classified into mainly positive and negative sentiments (Moreno-Marcos et al., 2018). The number of publications on sentiment analysis had significantly increased every year since the last decade (Sharef, 2014), including the study of MOOCs. In the field of MOOC, sentiment analysis enabled the provider/institution to have better insights into the learner's perception of the course.

By using the Excel Skills for Business Specialisation offered by Coursera as a case study, this study aims to classify MOOCs by using the eight dimensions from the Lai and Bower (2019) framework to investigate the participants' forum feedback on the official Coursera website. The main research question for this study is "What are the characteristics of a successful MOOC?" Ultimately, the study is intended to help researchers, educators and MOOC designers create new MOOCs which may improve the overall learning experience.

\section{Excel Skills for Business MOOCs}

Spreadsheet proficiency is one of the most critical workplace skills, especially in the business sector (Lee, Tang, Sam, \& Xiong, 2018). For example, a study shows that graduates in the finance sector often use spreadsheets in business settings (Tickle, Kyng, \& Wood, 2014). Another study about the skills requirements for graduates in accounting job advertisements indicates that Excel competency ranks the second highest, and this is the most highly requested computer skill (Dunbar, Laing, \& Wynder, 2016). Since digital skills, especially spreadsheet skills, are critical, upgrading these skills by attending training can improve the career prospect.

In June 2020, over 100 courses teaching Excel skills were offered by Coursera (Coursera Inc., 2020a). Among them, the Excel Skills for Business Specialisation was launched in November 2017 with over 100,000 learner enrolments since the launch. Excel Skills for Business Specialisation was designed for learners who sought to develop Excel skills. There were four courses in this specialisation, namely "Excel Skills for Business: Essentials", "Excel Skills for Business: Intermediate I", "Excel Skills for Business: Intermediate I", and "Excel Skills for Business: Advanced". At the end of the advanced course, learners would be able to create complex spreadsheets such as professional dashboards and conduct sophisticated calculations using advanced Excel features and techniques.

The program won the Outstanding Educator Award for Transformation in 2018, which recognised its significant impact on learners and their communities (Kolodny, 2018). Learners felt more confident in using spreadsheet in their day-to-day working life after studying the program (Koodny, 2018). In 2020, the program was rated 4.9 out of 5 by users (Coursera Inc., 2020b). By examining the practices of this successful Excel MOOC, it would help us identify the contributing factors of a high-rated MOOC.

\section{Previous work on evaluating the use of learning technology including MOOCs}

As previously mentioned, Lai and Bower (2019) conducted a review of 365 papers to determine which aspects of technology use in education were evaluated by researchers. Firstly, learning outcomes comprised an evaluation of knowledge, achievement, performance, or skills development (Hwang \& Tsai, 2011). Besides, affective elements were about learners' perceptions, intentions, preferences, attitudes and values (Rap \& Blonder, 2017). Behaviour consisted of participation, interaction or collaboration (Zhang, Liu, Chen, Wang, \& Huang, 2017). Technology was usually measured by its functionality, perceived usefulness and perceived ease of use (Han \& Shin, 2016). Design included course quality, course content, course structure and overall design (Sun, 2016). Teaching/pedagogy included pedagogical practices or teaching strategies (Martin, Budhrani, Kumar, \& Ritzhaupt, 2019). Presence included social presence, co-presence or community (Yang, 2016). Last but not least, the institutional environment took into account the institutional capacity, institutional intervention and support in facilitating the use of technology in teaching and learning (Snodgrass, Israel, \& Reese, 2016).

\section{Success factors of MOOCs}

Previous studies had investigated different aspects of effective MOOCs. For instance, in relation to learning outcomes, an effective MOOC course enabled learners to improve their skills as well as the level of knowledge 
in the subject area (Yousef, Chatti, Schroeder, \& Wosnitza, 2014). A systematic literature review showed that successful MOOCs should match the skills obtained by learners and required by future employers (Santandreu Calonge, Aman Shah, McGreal, and Conrad, 2016). Regarding affective elements, Yang (2014) expressed that student's motivation had a positive effect on the performance in a MOOC course. Xiong, Li, Kornhaber, Suen, Pursel and Goins (2015) investigated the relationships among motivation, course engagement and the success of MOOCs. With regard to the behavioural aspect, an effective MOOC learning environment allowed student-tostudent interaction (Watson, Watson, Richardson, Loizzo, McGreal \& Conrad, 2016). In other words, interactivity with other learners was critical in the MOOC context. However, researchers argued that not all MOOC platforms facilitated collaborative learning (Delurks, Indika and Shantha, 2020). Conole (2015) stated that MOOC design was a key factor in combating the low MOOC completion rates. A study of four computer Coursera courses indicated that course design and structure could impact student engagement (Sharma, Jermann, \& Dillenbourg, 2015). Also, the instructional design of MOOC would strongly influence the overall quality of the course (Margaryan, Bianco and Littlejohn, 2015). It was important to make sure the support structures were integrated into the MOOC design (Skrypnyk, de Vies, \& Hennis, 2015). Studies showed that in the MOOC environment, teaching staff would have a significant influence on learner engagement (Rai \& Chunrao, 2016; Ross, Sinclair, Knox, Bayne, \& Macleod, 2014). Regarding the social presence in the MOOC environment, Daniel (2012) argued that the dynamics of MOOCs created a challenging environment for stimulating and fostering peer interactions. In addition, the establishment of social presence was one of the crucial strategies to tackle the lack of interaction and engagement in MOOC environment (Poquet et al., 2018). Furthermore, research showed that instructors who actively supported the learners helped improve the overall learning experience with MOOCs (Hew, 2016). Similarly, Hone and El Said (2016) argued that instructor support and feedback in MOOCs positively impacted on learner retention.

Although there have been studies describing how MOOCs have been evaluated (Gamage, Perera, \& Fernando, 2016), researchers have expressed concern that there is insufficient literature focusing on factors that influence MOOCs' success, and more research is required to understand what constitutes a successful MOOC (Azevedo \& Marques, 2017). Hence, there is a need to understand the characteristics of successful MOOCs according to different dimensions.

\section{Methodology}

The methodology adopted in this paper is a case study approach which provides a multi-faceted understanding of the characteristics of MOOCs. In the following, we present the data collection process and explain how we analyse and characterise the Excel Skills for Business MOOCs.

\section{Data collection}

First of all, the learner feedback/comments posted from November 2017 to June 2020 on the public official website (https://www.coursera.org/learn/excel-essentials\#reviews) were harvested and analysed. Then, we characterised the Excel MOOCs by studying the actual course contents, materials and layout against the eight dimensions: learning outcomes, affective elements, behaviour, design, technology, teaching/pedagogy, presence/community and institutional environment. We also mapped the characteristics of the MOOC against the success factors mentioned in the literature review section, including skills enhancement, motivation, studentto-student interaction, course design, social presence and staff support.

\section{Data analysis}

To provide a comprehensive analysis of the perception of learners who attempted the MOOC course, we carried out a sentiment analysis by using the "auto-coding sentiments" function in Nvivo 12 Plus for all publicly available comments posted on the feedback forum. Sentiments could be coded as moderately positive, very positive, moderately negative and very negative (Nvivo, n.d.). Pudaruth, Moheeputh, Permessur, and Chamroo (2018) used the same Nvivo function to auto-code Facebook comments into different sentiment: positive, negative and neutral. Furthermore, we used the "text search function" in Nvivo to identify how many comments were related to the eight different aspects accordingly. We also included sub-dimensions of the eight different aspects when running the text search to ensure that the search covered all relevant areas that we would like to identify from the student comments. We complimented the text analysis by qualitatively examining and describing the course contents and materials to verify and triangulate the comments that participants had made. 
In the Results section, we presented the results of the sentiment analysis of learners' feedback/comments. Then, we showed how we mapped the text search results of learners' feedback/comments against the eight dimensions. Lastly, we provided the qualitative description and triangulation of the actual course contents, materials and layouts of the Excel MOOCs according to the eight dimensions using participant feedback.

\section{Results}

\section{Sentiment analysis of learners' feedback/comments}

There were over 4,521 reviews on the Excel MOOC website in June 2020. We only analysed those reviews which were written in English (4,486 reviews in total). Learners were generally satisfied with the courses. By using the auto-code function in Nvivo, 3,376 of them (74.7\%) were coded as "positive" emotion, with 1,509 very positive and 2,267 moderately positive. One of the "very positive" comments said, "this course is amazing, the way of teaching, step by step, no complicated information at once, great knowledge for the learner different backgrounds". In contrast, only 56 codes were classified as "negative" (1.2\%), with 37 and 19 of them regarded as moderately and very negative respectively. Among the negative feedback, learners sometimes disagreed with the "marking". The remaining reviews were neutral $(24.1 \%)$. The results indicated that there was an association between positive sentiment and overall liking of the course.

\section{Relationship between text search results and eight dimensions}

Besides, we used the text search function in Nvivo to investigate the focus of learners' comments/feedback. We realised that most of the comments were about learning outcomes (1,984 references), followed by affective elements (682), teaching/pedagogy (497), design (394) and technology (93). The remaining three dimensions, including institutional environment (26), behaviour (19) and presence/community (3), all had fewer than 50 references (Table 1). Table 2 showed the different sentiments among eight dimensions. Except for learning outcomes, affective elements and technology, all the other aspects only had positive emotions. Learners were especially impressed with the instructors' way of teaching. The results were consistent with the overall ratings that learners were generally satisfied with the Excel courses.

Table 1. Text search

\begin{tabular}{|c|c|c|c|c|c|c|c|c|}
\hline & $\begin{array}{l}\text { Learning } \\
\text { outcomes }\end{array}$ & $\begin{array}{l}\text { Affective } \\
\text { Elements }\end{array}$ & $\begin{array}{l}\text { Teaching/ } \\
\text { Pedagogy }\end{array}$ & Design & Technology & $\begin{array}{l}\text { Institutional } \\
\text { Environment }\end{array}$ & Behaviour & $\begin{array}{l}\text { Presence/ } \\
\text { Community }\end{array}$ \\
\hline $\begin{array}{l}\text { No. of } \\
\text { references } \\
\text { (with } \\
\text { stemmed } \\
\text { words) }\end{array}$ & 1,984 & 682 & 497 & 394 & 93 & 26 & 19 & 3 \\
\hline $\begin{array}{l}\text { Text search } \\
\text { (with } \\
\text { stemmed } \\
\text { words) }\end{array}$ & $\begin{array}{l}\text { Learning, } \\
\text { knowledge, } \\
\text { skills, } \\
\text { performance }\end{array}$ & $\begin{array}{l}\text { Engage, } \\
\text { motivate, } \\
\text { fun, insight, } \\
\text { recommend, } \\
\text { enjoy, } \\
\text { difficult, } \\
\text { confuse, } \\
\text { waste }\end{array}$ & $\begin{array}{l}\text { Teaching } \\
\text { strategy, } \\
\text { pedagogy, } \\
\text { teachers, } \\
\text { instructors }\end{array}$ & $\begin{array}{l}\text { Quality, } \\
\text { Content, } \\
\text { Structure, } \\
\text { Design }\end{array}$ & $\begin{array}{l}\text { Technology, } \\
\text { functionality, } \\
\text { compatibility, } \\
\text { technical } \\
\text { issues, } \\
\text { connections }\end{array}$ & $\begin{array}{l}\text { Institutional } \\
\text { environment, } \\
\text { policy, } \\
\text { institutional } \\
\text { support }\end{array}$ & $\begin{array}{l}\text { Usage, } \\
\text { interact, } \\
\text { collaborate, } \\
\text { self-regulate, } \\
\text { participate }\end{array}$ & $\begin{array}{l}\text { Presence, } \\
\text { social } \\
\text { presence, co- } \\
\text { presence, } \\
\text { community, } \\
\text { discussion }\end{array}$ \\
\hline
\end{tabular}

Table 2. Sentiments of different dimensions

\begin{tabular}{llllllll}
\hline & $\begin{array}{l}\text { Learning } \\
\text { outcomes }\end{array}$ & $\begin{array}{l}\text { Affective } \\
\text { elements }\end{array}$ & $\begin{array}{l}\text { Teaching/ } \\
\text { Pedagogy }\end{array}$ & Design & Technology & $\begin{array}{l}\text { Institutional } \\
\text { environment }\end{array}$ & $\begin{array}{c}\text { Behaviour } \\
\text { Presence/ } \\
\text { community }\end{array}$ \\
\hline $\begin{array}{l}\text { Very negative } \\
\begin{array}{l}\text { Moderately } \\
\text { negative }\end{array}\end{array}$ & 5 & 5 & 0 & 0 & 1 & 0 & 0 \\
$\begin{array}{l}\text { Moderately } \\
\text { positive }\end{array}$ & 624 & 14 & 0 & 3 & 7 & 0 & 0 \\
\begin{tabular}{l} 
Very positive \\
\hline
\end{tabular} & 587 & 350 & 187 & 170 & 34 & 9 & 11 \\
\end{tabular}

In addition to the overall picture of the sentiments of different dimensions, we investigated the course contents, materials and layouts of the Excel MOOCs by the eight dimensions in the following section to triangulate the results. Also, to further demonstrate our arguments, we quoted the actual feedback from those learners. Among 
the eight dimensions, learning outcomes was discussed first, followed by attitudes, behaviour, design, technology, teaching/pedagogy, presence/community and institutional environment.

\section{Evaluation of Excel MOOCs using eight dimensions}

Learning outcomes

Among the eight themes identified from the text search, learning outcomes were mentioned the most. A large proportion of learners indicated that the course was useful due to the authenticity and relevance of skills they were learning. For instance, learners obtained new skills like "how to take data from another sheet of the workbook". Learners also stated that the knowledge they acquired was useful ("After completing this course I can say that I was able to bring out a lot of useful tips and important knowledge"; "Course content and structure are excellent and helps one to learn at an optimal rate") and improved their day-to-day working life ("In just a couple of weeks I learned so many useful things which have already helped me to improve my daily tasks"; "This is a great course with a lot of practical exposure towards the routine issues faced by professionals like us").

In addition, the course provided learners with opportunities to acquire knowledge through hands-on experience ("It's really a good learning experience with hand-on practice section"; "I am finding new ways to implement my Excel knowledge every day through hand-on exercises"). In the long run, obtaining the Excel know-how in the course could increase learners' job prospects ("the course is good for those who want to learn Excel for boosting up their Career!'”).

Yet, the course could be improved in aspects like the level of difficulty of the contents ("I am hoping for more difficulty in the coming courses") and the provision of explanations relating to the answers ("Sometimes I feel answers should also be provided especially for the final assessment because in one of the questions I am getting a wrong answer and I am not able to find my mistake").

Affective elements

Learners in general had favourable learning experiences. They enjoyed the learning process and had fun ("Learning about printing from Excel, creating charts, and tools like Flash Fill and Freeze Pane was quite amazing and fun!"; "Awesome class - teaching basic concepts in a fun way with an eye to higher productivity and using shortcuts and performing steps without using the mouse").

Learners also found the course interesting so that they were motivated to learn ("it's very interesting and motivated me to learn"; "this course is excellent in all aspects to keep you motivated"). Besides, the built-in pop-up messages in different modules could keep learners motivated (Figure 2). Furthermore, once the learners had completed the course, they received a certificate as extrinsic motivation. Researchers believed that MOOC provided certificates as a means of promoting student engagement (Xiong et al., 2015).

Despite the generally positive feedback, some learners still believed that the course was not easy and too challenging ("but it was challenging"; "It's really difficult..., which is obviously disappointing”).

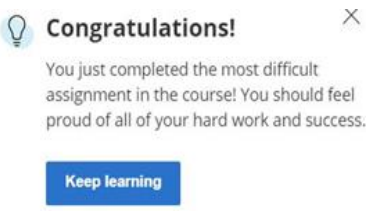

Figure 2. Pop up message

Behaviour

From the forum reviews, learners appreciated the interactivity nature of the course ("I loved the interaction and being able to follow along!"; "It is one of the most interactive online courses I have ever accomplished"). From observing the Excel MOOCs, we noticed that learners actively engaged in discussion forums, across all specialisations.

Besides, self-regulated learning was one of the most distinct characteristics of any MOOC course (Zhu, Bonk, \& 
Doo, 2020). Learners expressed that this course was useful especially for self-directed learning ("This course is a comprehensive refresher for self-taught excel users, who like to learn more about the many options excel has to work with data"; "Excellent course for beginners or for self-taught people needing guidance and a boost!'”). Learners could reflect and self-regulate their learning progress by checking the "track bars" thought the Excel MOOC interface (Figure 3). A calendar reminder was also useful for learner to keep track of important dates and assignment deadlines (Figure 4).
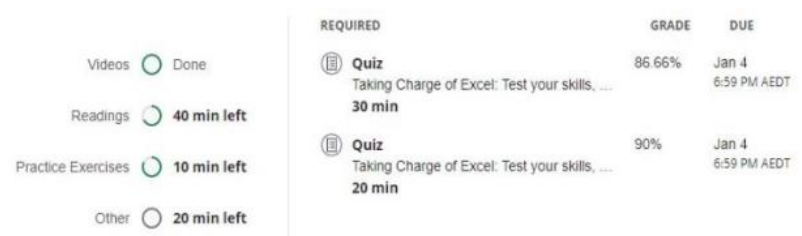

Figure 3. Indications of learning progress



Don't miss out on deadlines and events

Add all your assignment deadlines and important dates to your calendar. You can also set it up later in Settings.

Add to calendar $\vee \quad$ Set up later

Figure 4. A calendar reminder

Design

Learners in general perceived that the Excel MOOCs were well-organised and well-paced ("The course instructors have designed the course in a very organised way which helped me to find the small details that I have been looking all the time"; "An exceptionally well planned out introduction and overview to the fundamentals of Excel"; "The course was... well-paced, had clear and to-the-point videos and additional material”).

They also stated that the modules were logically structured ("The practice exercises allow to review the basic features and build solid bases before more advanced courses"). Learners found the assignments helpful which reinforced the concepts studied throughout the week ("Weekly assignments were very useful"; "There were good exercises to do before the assessments each week and before the final assessment"; "The content is divided in very small videos and after each video their practice video and assignment. So this makes the course more practical and easy to understand").

Yet, there was a suggestion regarding the length of the course ("The course was too long and time-consuming"; "It is 6-week course and since there is a lot of quizzes, it will take a long time to complete").

Technology

In the Excel MOOCs, learners generally felt that the interface of the Excel course was easy to use and understand ("Excellent user-interface"; "User-friendly interface... simple and detailed explanation"). Figure 5 showed the interface of the course. With the main topics shown on the left (e.g., weekly overview, grades, discussion forums) and the main contents in the middle of the screen, learners could easily navigate through various contents for different weeks.

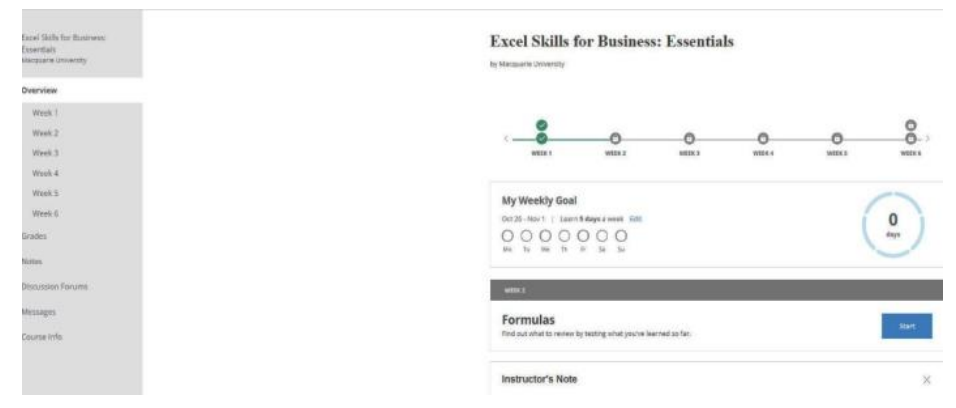

Figure 5. Course interface 
It was inevitable for learners to encounter technical issues in online learning (Pursel, Zhang, Jablokow, Choi, \& Velegol, 2016). For example, learners had problems with downloading the whole worksheet from the platform ("It only goes down 10 rows instead of the whole worksheet."). Also, there were some compatibility issues reported ("I had some compatibility issues with my 2007 version of Excel that made it difficult to score higher on certain quizzes").

\section{Teaching/Pedagogy}

According to the reviews, the Excel MOOC learners were satisfied with the pace of teaching and the effective teaching skills of the staff ("The instructors have explained in very good pace.... The way the instructors has explained all concepts hardly we need to view videos again, and everything is understood first time only";

"Tutor's way of teaching is nice, the flow of speaking is easy to understand and examples and materials provided in the course are good enough to practice each point thoroughly). They appreciated the friendliness of the teaching team and how they engaged with learners ("The lecturers were very friendly, easy to understand"; "The instructors are very much engaged with us in the course").

Furthermore, learners stated that the teachers' enthusiasm motivated them to learn ("The teachers also motivate you through challenges"; "Excellent Teaching - motivates you every time to practice more and more, which is the best way to retain, what you have learned"). Teachers were behaved in a professional manner ("Great course, professors are very professional").

\section{Presence/Community}

This Excel MOOC created a large learning community. Learners would be able to be present "socially" by actively engaging in discussion forums. For instance, a forum post in Week 1 aimed to help learners get to know each other had over 4,500 replies. This was a piece of clear evidence showing that the Excel course had created a large learning community. Also, learners thought that they were present in the classroom when they put "on headphones and starts the class".

\section{Institutional environment}

Studies showed that active participation of teaching staff in the discussion forum would positively influence the learning experience (Deslauriers, Schelew, \& Wieman, 2011). In the Excel MOOC course, student posts in the discussion forums were closely monitored by the staff. Learners also got adequate support from teaching staff ("Great course to get familiar with terms and issues that will arise with technical support"). Also, pop-up messages could provide instant support to learners. For instance, Figure 6 showed a pop-up message instructing the learner to click the sidebar icons to open lesson lists and notes. There was no obvious negative feedback about the institutional environment.

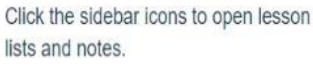

\section{Okay, got it!}

Figure 6. Pop-up instructions

\section{Discussion}

In the previous section, we have characterised the features of the Excel Skills for Business Specialisation according to the eight dimensions that have been demonstrated as comprehensive for evaluating technology use. From the course reviews, we notice that learners put much emphasis on learning contents/materials. The results resemble previous studies. For instance, a previous study demonstrated that learners who completed MOOC courses tended to be more interested in the course content (Wang \& Baker, 2015). Besides, learners in the Excel course highlighted the employability skills they had developed after attending the course. Santandreu Calonge, Aman Shah, McGreal, and Conrad (2016) argued that MOOC courses had the potential to assist learners to attain relevant skills before employment and continue to up-skill when employed. Nevertheless, some learners believed that more explanations should be given, especially in relation to why certain answers were wrong.

Regarding the attitude elements, learners were satisfied with the Excel MOOCs and felt more confident in using spreadsheets after the course. However, some learners still believed learning Excel was not an easy job and were not confident with their Excel skills. The teaching style was also a significant contributor to the success of the 
course. Learners in the Excel MOOCs enjoyed the way the instructors explained the concepts. Previous research also highlighted the critical aspect of the instructor's teaching strategy in a successful MOOC (Khalil \& Ebner, 2015; Rai \& Chunrao, 2016; Ross et al., 2014). In other words, MOOC teachers/instructors had a significant impact on learner satisfaction in MOOCs (Adamopoulos, 2013).

From the learner comments about the course design, it was revealed that they were satisfied with the Excel MOOCs because they thought that the course was well-organized, well-paced and clear-structured. Also, from the results of the text search by Nvivo, it was found that learners placed considerable emphasis on the design of the course aspect. The technological aspect of the MOOC course also contributed to the overall Excel MOOCs learning experience. The MOOC platform played a critical role in determining the access of the course on offer (Hood \& Littlejohn, 2016; Yousef et al., 2014). Learners agreed that the interface of the course was easy to follow with reliable content. However, learners occasionally encountered some compatibility issues with the software.

Learners interacting with each other could create a sense of social presence in the online learning environment (Poquet et al., 2018). Social presence was particularly critical in the MOOC environment (Bulu, 2012). In this Excel course, learners developed interpersonal connections with each other through weekly online discussion forums. Course forums provided learners with the opportunity to engage in social learning in MOOCs (Brinton et al., 2014). Regarding the institutional environment of the Excel course, learners expressed that they obtained adequate support from the teaching staff. If the institution provided enough support to learners, they would have a more positive overall experience (Hew, 2016). Regarding the behaviour aspect, learners interchanged ideas with each other in the Excel MOOC course mainly via Discussion Forums. A previous study showed that learners rated interactions in MOOCs as highly important to the overall satisfaction (Khalil \& Ebner, 2015). Also, as discussed above, the setting of the MOOC facilitated learners to have self-regulated learning.

\section{Conclusion}

This paper aims to categorize and evaluate a MOOC program and identify positive aspects of MOOCs. For the Excel MOOCs, approximately $75 \%$ of the unsolicited forum comments were positive. This sets a benchmark for other MOOCs in the field. Based on the analysis of student unsolicited feedback, the literature and the analysis of the Excel for Business MOOCs in this study, a successful MOOC should help learners increase their skills and improve their level of knowledge in the subject area. Besides, a good MOOC course can help improve learners' confidence in the subject and enhance their learning motivation. Learners should have the opportunity to interact with their peer and self-regulate their learning. The design of MOOC should be simple and easy to follow. The materials in the MOOC should be reliable, and the functionality should help learners understand the subject with ease. Teachers who provide clear explanations and demonstrations can make learning more efficient. This is especially critical in this particular case study. A good discussion forum enables learners to feel part of a community. Lastly, constant support from the institution should be given to learners. Some suggestions are provided by the learners to improve the course overall. For instance, they would like to have various levels of difficulty for the course. Also, compatibility with different versions of Excel is one concern from learners.

We have shown in this paper how to use Nvivo to auto-code the sentiments from the learners' comments. We have also demonstrated the running of text search with Nvivo to categorise the comments into eight different dimensions. However, our data are mainly confined to secondary sources, that is, learner feedback/comments from the public official Coursera website. The approach to combine both auto-code and text search may be used to analyse other online courses, provided that learner comments are available. To further characterise online learning in future, we are developing a robust instrument for evaluating technology use in education according to the eight dimensions, and shall use it to evaluate the Excel for Business MOOCs in our future research.

\section{References}

Adamopoulos, P. (2013). What makes a great MOOC? An interdisciplinary analysis of student retention in online courses. Proceedings International Conference on Information Systems, Milan. http://phd.meghansmith.com/wp-content/uploads/2016/04/What-Makes-a-Great-MOOC.pdf

Atiaja, L. A., \& Proenza, R. (2016). The MOOCs: origin, characterization, principal problems and challenges in Higher Education. Journal of e-Learning and Knowledge Society, 12(1), 65-71. 
Azevedo, J., \& Marques, M. M. (2017). MOOC success factors: Proposal of an analysis framework. Journal of Information Technology Education: Innovations in Practice, 16. https://repositorioaberto.up.pt/bitstream/10216/110462/2/248665.pdf

Brinton, C. G., Chiang, M., Jain, S., Lam, H., Liu, Z., \& Wong, F. M. F. (2014). Learning about social learning in MOOCs: From statistical analysis to generative model. IEEE Transactions on Learning Technologies, 7(4), 346-359.

Bulu, S. T. (2012). Place presence, social presence, co-presence, and satisfaction in virtual worlds. Computers \& Education, 58(1), 154-161.

Conole, G. (2015). Designing effective MOOCs. Educational Media International, 52(4), 239-252.

Coursera Inc. (2020a). Explore. https://www.coursera.org/search?query=Excel/

Coursera Inc. (2020b). Reviews - Excel Skills for Business: Essentials. https://www.coursera.org/learn/excelessentials\#reviews/

Daniel, J. (2012). Making sense of MOOCs: Musings in a maze of myth, paradox and possibility. Journal of Interactive Media in Education, 3(18). https://www.tonybates.ca/wp-content/uploads/Making-Sense-ofMOOCs.pdf

Deslauriers, L., Schelew, E., \& Wieman, C. (2011). Improved learning in a large-enrollment physics class. Science, 332(6031), 862-864.

Dilrukshi, G., Indika, P., \& Shantha, F. (2020). MOOCs lack interactivity and collaborativeness: Evaluating MOOC platforms. International Journal of Engineering Pedagogy, 10(2), 94-111.

Dunbar, K., Laing, G., \& Wynder, M. (2016). A content analysis of accounting job advertisements: Skill requirements for graduates. e-Journal of Business Education and Scholarship Teaching, 10(1), 58-72.

Gamage, D., Fernando, S., \& Perera, I. (2015). Factors leading to an effective MOOC from participiants perspective. Proceedings International Conference on Ubi-Media Computing (UMEDIA), Colombo, Sri Lanka. http://www.academia.edu/download/38248289/AEL__Camera_Ready.pdf

Gamage, D., Perera, I., \& Fernando, S. (2016). Evaluating effectiveness of MOOCs using empirical tools: Learners perspective. Proceedings International Technology, Education and Development Conference, Valencia, Spain. https://pdfs.semanticscholar.org/17b0/5acab2d18be484c180a1a3b68c1e04a01836.pdf

Gütl, C., Rizzardini, R. H., Chang, V., \& Morales, M. (2014). Attrition in MOOC: Lessons learned from dropout students. Communications in Computer and Information Science, 446, 37-48.

Han, I., \& Shin, W. S. (2016). The use of a mobile learning management system and academic achievement of online students. Computers \& Education, 102, 79-89.

Hew, K. F. (2016). Promoting engagement in online courses: What strategies can we learn from three highly rated MOOCS. British Journal of Educational Technology, 47(2), 320-341.

Hone, K. S., \& El Said, G. R. (2016). Exploring the factors affecting MOOC retention: A survey study. Computers and education, 98(C), 157-168.

Hood, N., \& Littlejohn, A. (2016). MOOC quality: The need for new measures. Journal of Learning for Development, 3(3), 28.

Hwang, G.-J., \& Tsai, C.-C. (2011). Research trends in mobile and ubiquitous learning: A review of publications in selected journals from 2001 to 2010. British Journal of Educational Technology, 42(4), E65E70.

Khalil, H., \& Ebner, M. (2015). "How satisfied are you with your MOOC?”-A research study about interaction in huge online courses. Journalism and mass communication, 5(12), 629-639.

Kolodny, T. (2018). 2018 Coursera Outstanding Educator Awards: Transforming lives with basic digital skills: insights from excel essentials for business. Coursera Blog. https://blog.coursera.org/transforming-livesbasic-digital-skills-insights-excel-essentials-business/

Lai, J., \& Bower, M. (2019). How is the use of technology in education evaluated? A systematic review. Computers and Education, 133, 27-42.

Lee, C., Tang, H., Sam, K., \& Xiong, G. (2018). Spreadsheet Proficiency: Which spreadsheet skills are important? Journal of Information Technology Management, 24(3), 35-44.

Loizzo, J., Ertmer, P. A., Watson, W. R., \& Watson, S. L. (2017). Adult MOOC learners as self-directed: Perceptions of motivation, success, and completion. Online Learning, 21(2), n2. https://files.eric.ed.gov/fulltext/EJ1149353.pdf

Margaryan, A., Bianco, M., \& Littlejohn, A. (2015). Instructional quality of Massive Open Online Courses (MOOCs). Computers and Education, 80(C), 77-83.

Martin, F., Budhrani, K., Kumar, S., \& Ritzhaupt, A. (2019). Award-winning faculty online teaching practices: Roles and competencies. Online Learning Journal (OLJ), 23(1), 184-205.

Moreno-Marcos, P. M., Alario-Hoyos, C., Muñoz-Merino, P. J., Estévez-Ayres, I., \& Kloos, C. D. (2018). Sentiment analysis in MOOCs: A case study. Proceedings IEEE Global Engineering Education Conference 
(EDUCON), Santa Cruz de Tenerife, Spain.

https://ieeexplore.ieee.org/stamp/stamp.jsp?tp=\&arnumber=8363409

Nvivo (n.d.) How auto coding sentiment works. http://help-nv11. qsrinternational. com/ desktop/ concepts/ How auto coding sentiment works.htm.

Poquet, O., Kovanović, V., de Vries, P., Hennis, T., Joksimović, S., Gašević, D., . . Blomgren, C. (2018). Social presence in Massive Open Online Courses. International Review of Research in Open and Distributed Learning, 19(3). http://www.irrodl.org/index.php/irrodl/article/view/3370/4686

Pudaruth, S., Moheeputh, S., Permessur, N., \& Chamroo, A. (2018). Sentiment analysis from Facebook comments using automatic coding in NVivo 11. Advances in Distributed Computing and Artificial Intelligence Journal, 7(1), 41-48.

Pursel, B. K., Zhang, L., Jablokow, K. W., Choi, G. W., \& Velegol, D. (2016). Understanding MOOC students: motivations and behaviours indicative of MOOC completion. Journal of Computer Assisted Learning, 32(3), 202-217.

Rai, L., \& Chunrao, D. (2016). Influencing factors of success and failure in MOOC and general analysis of learner behavior. International Journal of Information and Education Technology, 6(4), 262-268.

Rap, S., \& Blonder, R. (2017). Thou shall not try to speak in the Facebook language: Students' perspectives regarding using Facebook for chemistry learning. Computers \& Education, 114, 69-78.

Ross, J., Sinclair, C., Knox, J., Bayne, N., \& Macleod, H. (2014). Teacher experiences and academic identity: The missing components of MOOC pedagogy. Journal of Online Learning and Teaching, 10(1), 57. https://jolt.merlot.org/vol10no1/ross 0314.pdf

Santandreu Calonge, D., Aman Shah, M., McGreal, R., \& Conrad, D. (2016). MOOCs, graduate skills gaps, and employability: A qualitative systematic review of the literature. International Review of Research in Open and Distributed Learning, 17(5), 67-90.

Sharef, N. (2014). A review of Sentiment Analysis Approaches in Big Data Era. Proceedings Malaysian National Conference on Databases. Selangor, Malaysia.

Sharma, K., Jermann, P., \& Dillenbourg, P. (2015). Identifying styles and paths toward success in MOOCs. Proceedings International Conference on Educational Data Mining, Madrid, Spain. http://files.eric.ed.gov/fulltext/ED560766.pdf

Snodgrass, M. R., Israel, M., \& Reese, G. C. (2016). Instructional supports for students with disabilities in K-5 computing: Findings from a cross-case analysis. Computers \& Education, 100, 1-17.

Sun, J. (2016). Multi-dimensional alignment between online instruction and course technology: A learnercentered perspective. Computers \& Education, 101, 102-114.

Tickle, L., Kyng, T., \& Wood, L. N. (2014). The role of universities in preparing graduates to use software in the financial services workplace. International Journal of Mathematical Education in Science and Technology, 45(2), 200-213.

Walker, L., \& Loch, B. (2014). Academics' perceptions on the quality of MOOCs: An empirical study. International Journal for Innovation and Quality in Learning, 2(3), 53-63.

Wang, Y., \& Baker, R. (2015). Content or platform: Why do students complete MOOCs? Journal of Online Learning and Teaching, 11(1), 1-18.

Watson, S. L., Watson, W. R., Richardson, J., Loizzo, J., McGreal, R., \& Conrad, D. (2016). Instructor's use of social presence, teaching presence, and attitudinal dissonance: A case study of an attitudinal change MOOC. International Review of Research in Open and Distributed Learning, 17(3), 54-74.

Wen, M., Yang, D., \& Rose, C. (2014). Sentiment analysis in MOOC discussion forums: What does it tell us? Paper presented at the 7th International Conference on Educational Data Mining London, United Kingdom.

Xiong, Y., Li, H., Kornhaber, M. L., Suen, H. K., Pursel, B., \& Goins, D. D. (2015). Examining the relations among student motivation, engagement, and retention in a MOOC: A structural equation modeling approach. Global Education Review, 2(3), 23-33.

Yang, Q. (2014). Students motivation in asynchronous online discussions with MOOC mode. American Journal of Educational Research, 2(5), 325-330.

Yang, S.-H. (2016). Conceptualizing effective feedback practice through an online community of inquiry. Computers \& Education, 94, 162-177.

Yousef, A. M. F., Chatti, M. A., Schroeder, U., \& Wosnitza, M. (2014). What drives a successful MOOC? An empirical examination of criteria to assure design quality of MOOCs. Proceedings IEEE 14th International Conference on Advanced Learning Technologies, Athens, Greece. https://ieeexplore.ieee.org/stamp/stamp.jsp?tp=\&arnumber=6901394

Zhang, S., Liu, Q., Chen, W., Wang, Q., \& Huang, Z. (2017). Interactive networks and social knowledge construction behavioral patterns in primary school teachers' online collaborative learning activities. Computers \& Education, 104, 1-17. 
Zhao, Z., Wu Q., Chen H., Wan C. (2017) Learning Quality Evaluation of MOOC Based on Big Data Analysis. In: Qiu M. (eds) Smart Computing and Communication. SmartCom 2016. Lecture Notes in Computer Science, 10135. Springer, Cham. https://link.springer.com/chapter/10.1007/978-3-319-520155 28\#citeas

Zhu, M., Bonk, C. J., \& Doo, M. Y. (2020). Self-directed learning in MOOCs: exploring the relationships among motivation, self-monitoring, and self-management. Educational Technology Research and Development. https://doi.org/10.1007/s11423-020-09747-8

Lai, J. W. M., Bower, M., Breyer, Y. \& De Nobile, J. (2020). Investigating the characteristics of MOOCs according to eight critical dimensions: A case study. In S. Gregory, S. Warburton, \& M. Parkes (Eds.), ASCILITE's First Virtual Conference. Proceedings ASCILITE 2020 in Armidale (pp. 219-229).

https://doi.org/10.14742/ascilite2020.0115

Note: All published papers are refereed, having undergone a double-blind peer-review process.

The author(s) assign a Creative Commons by attribution licence enabling others to distribute, remix, tweak, and build upon their work, even commercially, as long as credit is given to the author(s) for the original creation.

(C) Lai, J. W. M., Bower, M., Breyer, Y. \& De Nobile, J. 2020 